\title{
Characterization of South African Isolates of Phytophthora infestans
}

A. McLeod, Agricultural Research Council (ARC)-Roodeplaat (Western Cape), Private Bag X1, Elsenburg, 7607, South Africa and Department of Plant Pathology, University of Stellenbosch, Private Bag X1, Matieland, Stellenbosch, 7602, South Africa; S. Denman, Department of Plant Pathology, University of Stellenbosch, Private Bag X1, Matieland, Stellenbosch, 7602, South Africa; A. Sadie, Department of Genetics, University of Stellenbosch, Private Bag X1, Matieland, Stellenbosch, 7602, South Africa; and F. D. N. Denner, ARC-Roodeplaat, Private Bag X1, Pretoria, 0001, South Africa

\begin{abstract}
McLeod, A., Denman, S., Sadie, A., and Denner, F. D. N. 2001. Characterization of South African isolates of Phytophthora infestans. Plant Dis. 85:287-291.

Severe late blight epidemics in South Africa in 1995 and 1996 prompted an investigation into the mating type, genotype, and metalaxyl sensitivity of populations of Phytophthora infestans. A country-wide survey was conducted from 1996 to 1998 in which isolates were collected from 101 potato fields (656 isolates) and 16 tomato fields (57 isolates). Six hundred and fifty-seven isolates (600 potato and 57 tomato) were analyzed for mating type, while subsets of isolates were analyzed for genotype at the Glucose-6-phosphate isomerase locus $(\mathrm{n}=148)$, DNA fingerprinting with probe RG-57 $(\mathrm{n}=61)$ and mitochondrial DNA haplotype $(\mathrm{n}=20)$. All isolates tested had the characteristics typical of the pre-1980 population (A1 mating type, 86/100 Gpi genotype, US-1 fingerprint pattern, and mtDNA haplotype I-b) previously found worldwide. Metalaxyl sensitivity testing of 656 potato isolates by the in vitro leaf disk method showed that the frequency of highly resistant isolates (50\% effective concentration $\left[\mathrm{EC}_{50}\right]>200 \mu \mathrm{g} \mathrm{a.i.} / \mathrm{ml}$ ) in potato production regions increased from $35 \%$ in 1996 to $51 \%$ in 1997. The high frequency of resistant isolates was confined to the southern coastal regions in 1996 and 1997, as well as the western Free State in 1997. Although phenylamides were withdrawn from the southern coastal region in December 1996, screening tests carried out in 1998 indicated that resistance levels remained high ( $\geq 83 \%)$. Sensitive isolates $\left(\mathrm{EC}_{50}<40 \mu \mathrm{g}\right.$ a.i./ml) predominated in the remaining six potato production regions. Screening of 45 isolates collected from tomatoes indicated that no resistant strains were present in the sample tested.
\end{abstract}

Late blight caused by Phytophthora infestans (Mont.) de Bary is one of the most important potato (Solanum tuberosum L.) and tomato (Lycopersicon esculentum Mill.) diseases worldwide due to rapid asexual reproduction of the pathogen under conducive weather conditions (14). P. infestans is heterothallic, having two mating types, A1 and A2, and can reproduce sexually and asexually $(15,16)$. Before the late 1970s, the A2 mating type was only found in central Mexico, so that no sexual reproduction (out-crossing) between A1 and A2 mating types was possible outside Mexico (23). However, with the second migration of $P$. infestans from its presumed center of origin, Mexico, in the late 1970s, sexual reproduction became possible due to the migration of A2 mating types. The migration also resulted in major population dis-

Corresponding author: Adele McLeod

E-mail: am229@cornell.edu

Current address of A. McLeod: Department of Plant Pathology, Cornell University, Ithaca, NY 14853.

Accepted for publication 13 November 2000.

Publication no. D-2000-1219-01R

(C) 2001 The American Phytopathological Society placements and genetic changes in populations outside Mexico $(19,32)$.

The pan-globally distributed clonal lineage, termed US-1 (or PO-1), that was present prior to 1970 was rapidly displaced by new genetically diverse genotypes almost worldwide (19). The presence of these new genotypes resulted in renewed research on the pathogen since it could then reproduce sexually due to the added presence of the A2 mating type, and new populations demonstrated increased aggressiveness $(13,24,25)$. The presence of phenylamide (metalaxyl) resistant isolates in new populations further added to the devastation and control problems associated with new populations $(6,20)$. Phenylamide fungicides were the only systemic fungicides with protective action as well as curative activity available for late blight control (7).

In South Africa, potato production is a major industry with 53,872 ha of seed and table potatoes planted in 1998 and 56,828 ha in 1999 in the 11 main production regions. Approximately $74 \%$ of the potatoes are under irrigation, and the rest is dry-land production. Prior to 1995, late blight was not prevalent in most of the potato production regions, especially in the northern regions and noncoastal regions. In these regions, the erratic occurrence of the dis- ease and sunny spells after conducive weather aided disease control, so that potato producers used curative fungicide spray programs predominantly to control late blight. Curative spray programs consisted mainly of weekly sprays of phenylamide-containing products (4 to 10 sprays) (Niel Theron, Potatoes South Africa, Private Bag X 135, Pretoria 0001, South Africa, personal communication).

In 1995 and 1996, severe late blight epidemics were experienced in almost all the potato and a few tomato production regions in South Africa, together with conducive late blight weather. The epidemics were further characterized by new symptoms of black streaking of potato stems similar to Erwinia infection, but $P$. infestans sporulated profusely from stem lesions when incubated in moist chambers (A. McLeod, unpublished data). The severe epidemics might have been ascribed to a number of causes, such as incorrect spray programs, pathogen resistance to phenylamides, conducive weather conditions, new genotypes, or a combination of these. The exact cause of these severe blight epidemics was difficult to establish since producers often use curative spray programs (average two to three phenylamide sprays and up to five sprays per season), making the evaluation of fungicide efficacy difficult. However, control problems were also experienced by producers who used correct spray programs, indicating that incorrect spray programs were not the only reason for the epidemics. Therefore, these severe epidemics and new symptoms were thought to be caused by new $P$. infestans populations that had also been recently reported to cause devastating epidemics worldwide $(6,13)$. These populations might have been introduced on latently infected potato tubers imported to South Africa in the early 1980s (Niel Theron, Potato South Africa, personal communication) from the Netherlands, where 35 new RG-57 genotypes have been identified $(10,12)$. To determine which factors contributed to the severe and difficult-to-control epidemics, a study was initiated to establish whether the reported correlation between disease severity and genotype (mating type, allozyme and fingerprinting composition) from Europe and North America was also characteristic of the severe late blight epidemics in South 
Africa, and/or whether failure to control disease could be attributed to phenylamideresistant populations in the different production regions.

\section{MATERIALS AND METHODS}

Sample collection and isolation. $P$. infestans-infected leaves and stems were collected from fields in the different potato and tomato production regions in South Africa during 1996 and 1997 (Fig. 1). During 1998, late blight infected potato material was collected only from the southern Cape, southwestern Cape, and Sandveld (hereafter referred to as southern coastal region) (Fig. 1). From each field, 1 to 15 leaves/stems (depending on the infestation level in the field) were collected within a radius of $\pm 100 \mathrm{~m}$. From this sample, subsamples of 1 to 10 leaves were surface-sterilized for $3 \mathrm{~min}$ in $0.5 \%$ sodium hypochlorite $(\mathrm{NaOCl})$ and placed in moist chambers. After incubation for $24 \mathrm{~h}$ at $18^{\circ} \mathrm{C}$, a mass of sporangia was transferred with a sterile glass rod to wheat medium (120 g of crushed pearled wheat seeds, blended, boiled, and filtered, plus $15 \mathrm{~g}$ of sucrose and agar, per liter) amended with $0.03 \mathrm{~g}$ of rifampicin per liter and $0.03 \mathrm{~g}$ of benomyl per liter $(50 \%$ a.i./ml). Hence,

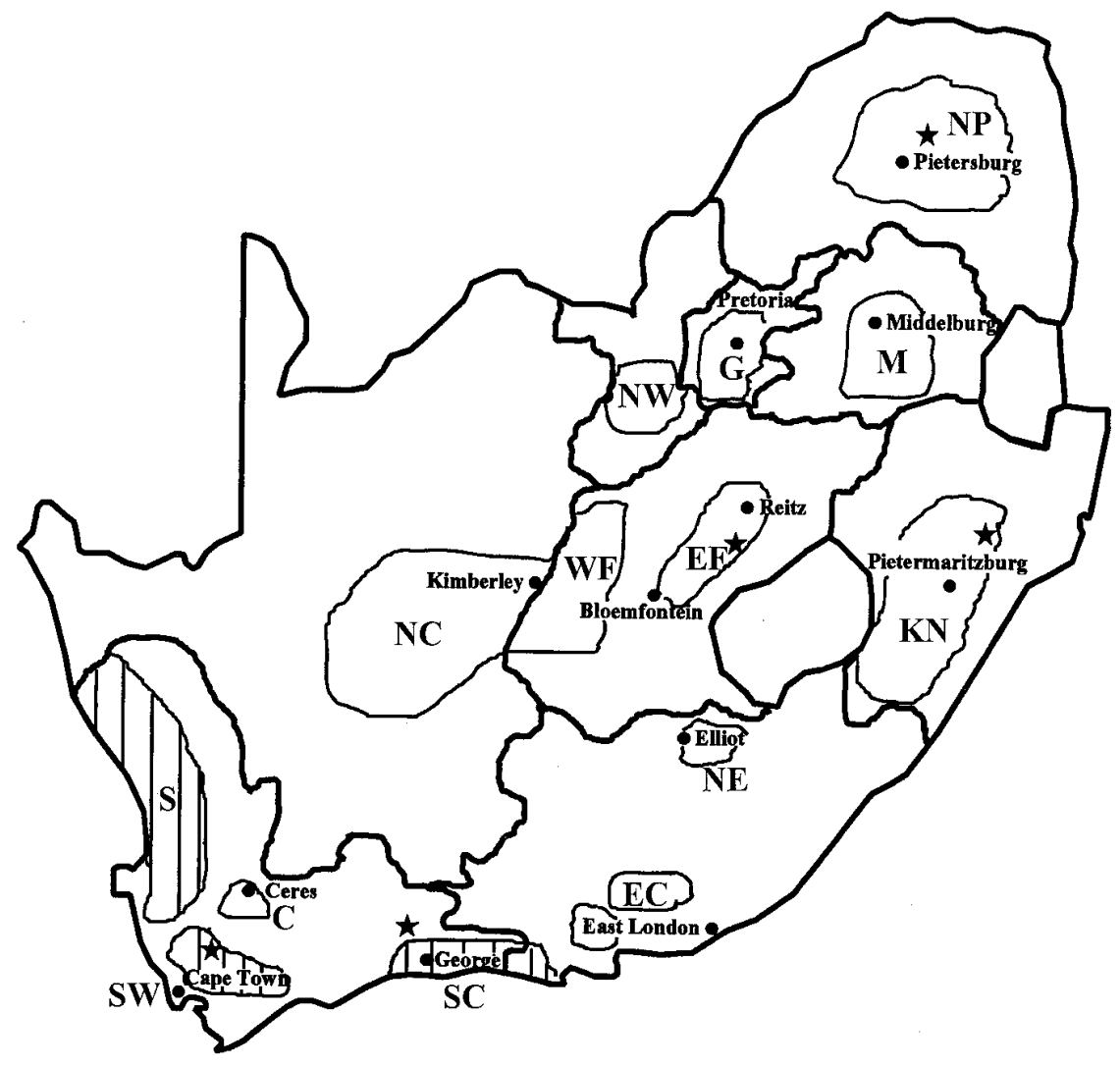

Fig. 1. Location of potato production regions in South Africa where Phytophthora infestans isolates were collected. $\mathrm{S}=$ Sandveld, $\mathrm{C}=$ Ceres, $\mathrm{SW}=$ southwestern Cape, $\mathrm{NC}=$ Northern Cape, $\mathrm{EC}=$ Eastern Cape, WF = western Free State, EF = eastern Free State, KN = Kwazulu-Natal, M = Mpumalanga, $\mathrm{NP}=$ Northern Province, $\mathrm{NW}=$ northwest, $\mathrm{SC}=$ southern Cape, $\mathrm{G}=$ Gauteng, $\mathrm{NE}=$ north Eastern Cape. Hatchmarks $=$ southern coastal regions. Star $=$ regions where tomato samples were collected.

isolates derived from single lesions were cultured separately and stored in liquid nitrogen and on wheat agar slants covered with mineral oil at $5^{\circ} \mathrm{C}$ until needed for subsequent research.

Mating type testing. Mating types of 600 potato isolates (Table 1) and 57 tomato isolates (Table 2) were determined by pairing isolates of $P$. infestans with known A1 and A2 mating strains on $10 \%$ clarified V8 medium (33). Oospore formation was checked after 10 days incubation at $18^{\circ} \mathrm{C}$ in the dark, using a microscope. Isolates which formed oospores with the known A2 isolate were designated as A1 isolates and vice versa. Known $\mathrm{A} 1$ and $\mathrm{A} 2$ mating type isolates were provided by G. A. Forbes (International Potato Centre in Quito, Ecuador).

Gpi analysis. For glucose-6-phosphate isomerase (Gpi, EC 5.3.1.9) analysis, a subset of 148 isolates (134 potato and 14 tomato) was cultured in liquid wheat medium (as above but without agar) in 9-cmdiameter petri plates (two plates per isolate) for approximately 14 days at $18^{\circ} \mathrm{C}$ in the dark. Harvested mycelium was ground to a powder with a mortar and pestle cooled with liquid nitrogen and stored at $-80^{\circ} \mathrm{C}$ until further use.

Polyacrylamide gel electrophoresis was performed in a Hoefer SE 250 Mighty Small II mini-vertical system using isoelectric focusing (pharmalyte, $\mathrm{pH} 5$ to 6) $(22,30)$. Crushing buffer $(0.1 \mathrm{M}$ Tris- $\mathrm{HCl}$, $\mathrm{pH} 6.7$ + dithiotreitol [2 $\mathrm{mg} / \mathrm{ml}])$ was added to crushed mycelium before centrifuging at $14,000 \mathrm{rpm}$ for $20 \mathrm{~min}$. Glycerol was added to a final concentration of $25 \%$ to the supernatant. Seventeen microliters of the supernatant of each sample was loaded on a $5 \%$ polyacrylamide gel. Gels were run for $1 \mathrm{~h}$ at $200 \mathrm{~V}$ followed by $1 \mathrm{~h}$ at $400 \mathrm{~V}$ at a constant temperature of $15^{\circ} \mathrm{C}$. Gpi was detected using the technique of Oudemans and Coffey (29). Reference isolates US940501, NE890053, US940480, CA920022, and US940486, representing Gpi genotypes 86/100, 90/100, 100/111/ 122 , and $100 / 111$, respectively, were used. Reference isolates were provided by W. E. Fry (Cornell University, Ithaca, NY).

DNA fingerprinting. Nuclear fingerprinting of 61 isolates was determined

Table 1. Number of Phytophthora infestans isolates collected for mating type testing from fields in different potato production regions in South Africa

\begin{tabular}{|c|c|c|c|c|c|c|}
\hline \multirow{2}{*}{$\begin{array}{l}\text { Potato production } \\
\text { region }\end{array}$} & \multicolumn{2}{|c|}{1996} & \multicolumn{2}{|c|}{1997} & \multicolumn{2}{|c|}{1998} \\
\hline & No. of fields & No. of isolates & No. of fields & No. of isolates & No. of fields & No. of isolates \\
\hline Eastern Free State & 4 & 42 & 5 & 21 & 0 & 0 \\
\hline Western Free State & 6 & 40 & 5 & 28 & 0 & 0 \\
\hline Northwest & 3 & 9 & 0 & 0 & 0 & 0 \\
\hline Mpumalanga & 3 & 18 & 3 & 18 & 0 & 0 \\
\hline Gauteng & 0 & 8 & 0 & 0 & 0 & 0 \\
\hline Sandveld & 10 & 44 & 10 & 85 & 9 & 42 \\
\hline Southwestern Cape & 3 & 16 & 1 & 16 & 1 & 6 \\
\hline Southern Cape & 6 & 37 & 6 & 34 & 2 & 6 \\
\hline Northern Province & 2 & 13 & 0 & 0 & 0 & 0 \\
\hline Kwazulu-Natal & 9 & 44 & 11 & 69 & 1 & 3 \\
\hline Eastern Cape & 0 & 0 & 1 & 1 & 0 & 0 \\
\hline
\end{tabular}


using the moderately repetitive genomic clone RG57 (18). Isolates tested for fingerprinting were chosen to represent all geographical regions, different sampling dates, and different metalaxyl sensitivities. Southern blot analysis with RG57 was done using the Renaissance nonradioactive detection kit as described by the manufacturer (New England Nuclear, Boston, MA) (31).

Mitochondrial DNA haplotype. The PCR method of Griffith and Shaw (21) using primers pairs 1,2 , and 4 , was used to determine the mtDNA haplotype of 20 isolates. Isolates tested for mitochondrial DNA haplotype were chosen so that they represented all the geographical regions, different sampling dates and different metalaxyl sensitivities.

Evaluation of phenylamide sensitivity by the in vitro leaf disk method using EC $_{50}$ (concentration at which $\mathbf{5 0 \%}$ growth reduction occurred) values. Six hundred and fifty-six single-lesion $P$. infestans isolates collected from 1996 to 1998 in different potato production regions and 45 isolates collected from tomato were tested for phenylamide sensitivity by the in vitro leaf disk method. A stock solution of metalaxyl at $1,000 \mu \mathrm{g}$ a.i./ml (96\% purity) was made by dissolving the metalaxyl in $100 \mu \mathrm{l}$ of ethanol (98\%) and then adding 1 liter of water. The stock solution was diluted to concentrations of $750,500,250$, $100,10,1$, and $0.1 \mu \mathrm{g}$ a.i./ml. Ten disks, 11 $\mathrm{mm}$ in diameter, were cut from leaves of potato cultivar Up-to-date (3- to 7-weekold plants) and floated with their abaxial surface uppermost in 65-mm petri dishes (two dishes with five disks each per isolate) at each fungicide concentration. Controls were disks floating on sterile water containing no fungicide. Sporangia suspensions were made from 7- to 14-day-old cultures, and each disk was inoculated with a sporangial suspension drop $(20 \mu \mathrm{l})$ containing 2 to $10 \times 10^{4}$ sporangia per $\mathrm{ml}$ that had been induced to release zoospores by incubation at $4^{\circ} \mathrm{C}$ for $2 \mathrm{~h}$. Inoculated disks were placed at 16 to $18^{\circ} \mathrm{C}$ with a 12 -h photoperiod for 6 days. Disease severity on the disks was rated using a scale of $0,1,3$, 5,7 , or 9 , representing $0 \%, 1$ to $20 \%, 21$ to $40 \%, 41$ to $60 \%, 61$ to $80 \%$, and 81 to $100 \%$ of the disk surface covered with mycelial growth, respectively. One known sensitive isolate (TB1.4, LE 6.2, or OF3) obtained from potato fields in South Africa in 1996 was included in each screening test to detect false positive resistance testing of isolates. The $\mathrm{EC}_{50}$ value of isolates was determined by plotting the disease severity ratings against concentration of fungicide for each isolate tested. The most suitable regression function (linear, log, exponential, or inverse) was fitted to the plots of each isolate, and the concentration at which $50 \%$ growth reduction $\left(\mathrm{EC}_{50}\right)$ of the isolate could be expected was calculated. The program Statistical Analysis System release 6.11 (SAS, Cary, NY) was used. Isolates that had an $\mathrm{EC}_{50}$ value higher than $200 \mu \mathrm{g}$ a.i. $/ \mathrm{ml}$ were classified as resistant, and those having an $\mathrm{EC}_{50}$ value less than $40 \mu \mathrm{g}$ a.i./ml were classified as sensitive.

\section{RESULTS}

All South African isolates were monomorphic for the neutral markers assayed. All 657 isolates ( 600 potato and 57 tomato) obtained from 101 potato fields and 16 tomato fields were A1 mating type. Of the subset of 148 isolates (70 metalaxyl resistant and 78 metalaxyl sensitive isolates) analyzed for genotype at the Gpi locus, all were $86 / 100$. Reference isolates that were used in the allozyme analysis all showed the expected banding patterns (Fig. 2). Sixty-one isolates (representing the different geographical regions, sampling dates, and metalaxyl sensitivities) subjected to DNA fingerprinting to RG57 had the US-1 pattern, and all 20 isolates (10 metalaxyl resistant and 10 metalaxyl sensitive isolates) assayed for mtDNA had haplotype Ib. The patterns were exactly the same as those obtained with the standard US-1 reference isolate.

However, there was variation for metalaxyl sensitivity in the US- 1 popula- tion in South Africa. Two main groups, a highly resistant group with $\mathrm{EC}_{50}$ values in excess of $200 \mu \mathrm{g}$ a.i./ml and a sensitive group with $\mathrm{EC}_{50}$ values less than $40 \mu \mathrm{g}$ a.i./ml, were identified. The mean frequency of highly resistant isolates $\left(\mathrm{EC}_{50}>\right.$ $200 \mu \mathrm{g}$ a.i./ml) in all the potato production regions increased from 35\% in 1996 to $51 \%$ in 1997 (Table 3). However, resistant isolates were confined to certain potato production regions (Table 3 ). The frequency of resistant isolates was high $(>66 \%)$ in the southern coastal regions during 1996 and 1997. In the western Free State, resistance was absent in 1996 but emerged at $74 \%$ in 1997 . Ninety-eight percent of the isolates that were collected in 1998 from the southern coastal regions were still highly resistant $\left(\mathrm{EC}_{50}>200 \mu \mathrm{g}\right.$ a.i./ml) (Table 3). Resistance was absent or very low $(<13 \%)$ in all six remaining potato production regions in 1996 and 1997 (Table 3).

The 45 isolates of $P$. infestans collected from tomatoes in 1996 and 1997 were all highly sensitive to metalaxyl, and no resistant isolates were identified. The mean $\mathrm{EC}_{50}$ values of isolates in all the tomato production areas were very low compared with mean $\mathrm{EC}_{50}$ values of potato isolates in

Table 2. Number of Phytophthora infestans isolates collected for mating type testing from fields in different tomato production regions of South Africa

\begin{tabular}{lccccc}
\hline \multirow{2}{*}{$\begin{array}{l}\text { Tomato } \\
\text { production region }\end{array}$} & \multicolumn{2}{c}{$\mathbf{1 9 9 6}$} & & \multicolumn{2}{c}{1997} \\
\cline { 2 - 3 } \cline { 5 - 6 } \cline { 5 - 6 } & No. of fields & No. of isolates & & No. of fields & No. of isolates \\
\hline Kwazulu-Natal & 6 & 33 & & 3 & 13 \\
Eastern Free State & 1 & 1 & & 0 & 0 \\
Northern Province & 2 & 3 & & 2 & 0 \\
Southern Cape & 0 & 0 & & 1 & 3 \\
Southwestern Cape & 0 & 0 & & 1 & 4 \\
\hline
\end{tabular}

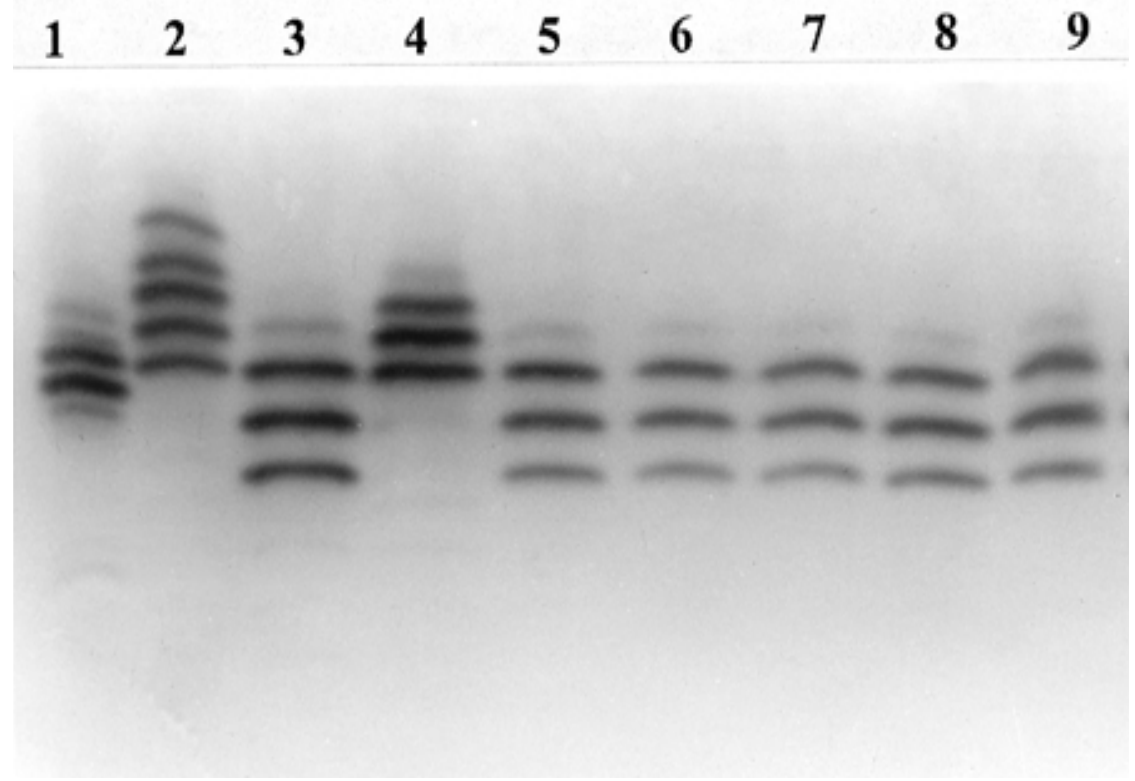

Fig. 2. Polyacrylamide gel stained for glucose-6-phosphate isomerase (Gpi) genotypes of Phytophthora infestans. Gpi genotypes of $P$. infestans isolates are in lanes from left to right: (1) 90/100 (NE890053), (2) 100/111/122 (US949480), (3) 86/100 (CA920022), (4) 100/111 (US940486), (5 to 8) 86/100 (South African isolates), (9) 86/100 (US940501). 
the same area, especially in the southern Cape and southwestern Cape (Table 4).

\section{DISCUSSION}

The presence of only the A1 mating type, $86 / 100$ banding pattern for Gpi, mtDNA haplotype I-b, and US-1 fingerprint pattern in $P$. infestans populations in South Africa indicate that the South African population still belongs to the historical clonal lineage previously found worldwide $(14,17,21)$. The absence of the A2 mating type in SA restricts the pathogen to asexual reproduction. New gene combinations and increased survival via oospores associated with sexual reproduction, as well as increased aggressiveness associated with new populations $(13,25,27)$, are thus not yet a reality for potato and tomato production in South Africa.

The increased severity of late blight epidemics in South Africa is attributed, in part, to the occurrence of metalaxylresistant populations. Metalaxyl sensitivity testing revealed that $35 \%$ of the potato isolates tested in 1996 were resistant, as were $51 \%$ tested in 1997 . The occurrence of a high frequency of resistant isolates on potatoes was, however, confined to the southern coastal regions, as well as the western Free State (only in 1997). The high levels of resistance found in the southern coastal regions probably can be attributed to the following factors: (i) phenylamides were applied through pivot irrigation, rendering the anti-resistance strategy of co-formulation with a dithiocarbamate ineffective, because the dithiocarbamate and phenylamide are washed from leaves, with only the phenylamide taken up by roots and protecting the plant; (ii) up to five applications per planting were applied within these continuous cropping systems (potatoes planted 12 months of the year) so that populations were under constant selection pressure throughout the year; (iii) blight-favorable weather occurred consistently and was further aggravated by pivot irrigation at night; and (iv) susceptible cultivars were cultivated.

Table 3. Number of Phytophthora infestans isolates collected for metalaxyl sensitivity assessment from farms in different potato production regions and percent metalaxyl resistant isolates in each region

\begin{tabular}{|c|c|c|c|}
\hline Production region & $\begin{array}{c}\text { No. of farms } \\
\text { surveyed }\end{array}$ & $\begin{array}{c}\text { No. of isolates } \\
\text { collected }\end{array}$ & $\begin{array}{l}\% \text { Metalaxyl } \\
\text { resistant isolates }\end{array}$ \\
\hline \multicolumn{4}{|l|}{1996} \\
\hline Gauteng & 2 & 7 & 0 \\
\hline Mpumalanga & 4 & 24 & 13 \\
\hline Kwazulu-Natal & 9 & 45 & 4 \\
\hline Northern Province & 2 & 13 & 8 \\
\hline Northwest & 3 & 8 & 0 \\
\hline Eastern Free State & 4 & 36 & 0 \\
\hline$*$ Sandveld & 11 & 52 & 96 \\
\hline * Southern Cape & 6 & 33 & 73 \\
\hline * Southwestern Cape & 3 & 16 & 94 \\
\hline Western Free State & 6 & 34 & 0 \\
\hline Total & 50 & 268 & 35 \\
\hline \multicolumn{4}{|l|}{1997} \\
\hline Mpumalanga & 2 & 10 & 0 \\
\hline Kwazulu-Natal & 11 & 69 & 1 \\
\hline Northwest & 1 & 3 & 0 \\
\hline Eastern Free State & 5 & 21 & 0 \\
\hline * Sandveld & 10 & 63 & 100 \\
\hline * Southern Cape & 6 & 30 & 97 \\
\hline * Southwestern Cape & 1 & 9 & 67 \\
\hline Western Free State & 5 & 27 & 74 \\
\hline Total & 41 & 232 & 51 \\
\hline \multicolumn{4}{|l|}{1998} \\
\hline * Sandveld & 12 & 100 & 100 \\
\hline * Southwestern Cape & 1 & 28 & 99 \\
\hline * Southern Cape & 1 & 28 & 100 \\
\hline Total & 14 & 156 & 100 \\
\hline
\end{tabular}

$\mathrm{a} *=$ Potato production regions forming the southern coastal regions.

Table 4. Mean 50\% effective concentration $\left(\mathrm{EC}_{50}\right)$ values for metalaxyl sensitivity for Phytophthora infestans isolates collected from potato and tomato in the same production region

\begin{tabular}{lcc}
\hline Production region & $\begin{array}{c}\text { Mean } \mathbf{E C}_{\mathbf{5 0}} \text { value } \\
\text { of tomato isolates }\end{array}$ & $\begin{array}{c}\mathbf{E C}_{\mathbf{5 0}} \text { value } \\
\text { of potato isolates }\end{array}$ \\
\hline Kwazulu-Natal & 0.53 & 11.42 \\
Northern Province & 0.05 & 2.67 \\
Eastern Free State & 0.04 & 7.51 \\
Southern Cape & 0.04 & 359.93 \\
Southwestern Cape & 0.49 & 397.98 \\
\hline
\end{tabular}

Monitoring of $P$. infestans isolates in the southern coastal regions showed that resistance levels remained high. The high resistance levels found in this study prompted the phenylamide work group of the Fungicide Resistance Action committee (FRAC) in South Africa to withdraw the products from the southern coastal regions in December 1996 until resistance levels decreased. Surveys conducted in June/July 1997 and in 1998 showed that resistance levels remained high and that levels even increased in some regions. The continued high levels of resistance in two consecutive years after product withdrawal differs from the situation in Europe, where there was a general tendency toward a decrease in frequency of phenylamideresistant isolates in consecutive seasons in the early 1980 s $(2,3,5,9)$. The continued high levels of resistance in South Africa corresponds to U.S. data $(8,13)$, except that no immigrating strains have been found in South Africa, where only the old US-1 lineage was identified.

Volunteer plants from infected seed tubers are often the main source of inoculum for blight outbreaks in subsequent potato crops (1). Therefore, the initial levels of resistant isolates at the start of an epidemic are greatly influenced by the frequency of metalaxyl-resistant $P$. infestans isolates present in seed potatoes (4). In the western Free State production region, potatoes are only cultivated during the summer, using seed potatoes produced either in the Sandveld or in the western Free State. The increase in resistant strains from 0\% in 1996 to $74 \%$ in 1997 in the western Free State might have been due to infected seed tubers from the Sandveld, because high levels of resistance were present very early in the season, before phenylamides had been applied. Since high levels (90 to $100 \%$ ) of resistance have been found in the Sandveld, which is the largest seed production region in South Africa, phenylamideresistant strains are bound to migrate from this area to other production regions through infected seed. The current high levels of resistance in two major seed production regions (Sandveld and western Free State) greatly increase the risk of spread of resistant strains to other production regions. Monitoring for metalaxyl resistance in all potato production regions must therefore be continued to establish whether resistance levels will decrease with resistance management strategies in the regions with high levels of resistance, and whether resistant isolates from seed production regions are spreading to other production regions where only sensitive isolates were previously found.

In the old US-1 populations, metalaxyl resistance was rarely found, and if present only to a limited extent $(6,11,14,34)$. A few US-1 isolates from the Philippines were previously reported to be metalaxyl resistant (26). Metalaxyl resistance is, however, 
frequently associated and reported in new populations $(6,20)$. The widespread occurrence of highly resistant isolates in the US1 population in South Africa that remained stable over 2 years shows that metalaxyl resistance can readily develop within the US-1 lineage under high selection pressure (two to three sprays per season with three growing seasons per year).

The absence of metalaxyl resistance in tomato isolates has also been found in the Netherlands (12). The absence of metalaxyl resistant isolates on tomatoes in the southern coastal potato production regions in South Africa, where high levels of resistance have been found on potato, indicates that the source of resistant isolates on potatoes was not tomatoes. Seemingly, two subpopulations of the US-1 populations are present in South Africa, i.e., metalaxyl sensitive and metalaxyl resistant, which might be explained by host preference of $P$. infestans isolates. Host preference of $P$. infestans suggests that while all isolates are pathogenic on potato, only some isolates are pathogenic on tomato (28).

Based on the results of the survey reported here, it seems that the increased aggressiveness of $P$. infestans populations in South Africa cannot be attributed to migration of new genotypes. The increased severity of epidemics in South Africa is rather attributed to conducive weather patterns during the 1995-96 growing season, widespread phenylamide resistance in certain potato production regions, and most probably incorrect spray programs. Strict control measures must be taken to prevent future entry of the A2 mating strain and isolates from new populations of $P$. infestans into South Africa. Although the importation of only test-tube and/or greenhouse tubers has been allowed since June 1997 by law, the introduction of new genotypes cannot be totally excluded due to illicit importations across borders. This remains a real threat, since new $P$. infestans genotypes have been found in Africa (Rwanda) (17), and it is probably only a matter of time before these populations migrate southward.

\section{ACKNOWLEDGMENTS}

We thank "Potatoes South Africa" for financially supporting this research and Niel Theron for useful discussions. We also thank W. E. Fry for helpful discussions, comments, and funding of the DNA work.

\section{LITERATURE CITED}

1. Bain, R. A., and Holmes, S. J. 1990. Phenylamide use on seed potato crops and resistance in Phytophthora infestans isolated from progeny tubers. Brighton Crop Prot. Conf. Pests Dis. 9:1121-1126.

2. Bradshaw, N. J., and Vaughan, T. B. 1996. The effect of phenylamide fungicides on the control of potato late-blight (Phytophthora infestans) in England and Wales from 1978 to 1992. Plant Pathol. 45:249-269.

3. Cooke, L. R., and Penney, R. E. 1992. Phenylamide resistance in Phytophthora infestans in Northern Ireland - A changing situation. Brighton Crop Prot. Conf. 3:201-206.

4. Davidse, L. C., Daniel, D. L., and Van Westen, C. L. 1983. Resistance to metalaxyl in Phytophthora infestans in the Netherlands. Neth. J. Plant Pathol. 89:1-20.

5. Davidse, L. C., Henken, J., Van Dalen, A., Jespers, A. B. K., and Mantel, B. C. 1989. Nine years of practical experience with phenylamide resistance in Phytophthora infestans in the Netherlands. Neth. J. Plant Pathol. 95(Suppl. 1):197-213.

6. Day, J. P., and Shattock, R. C. 1997. Aggressiveness and other factors relating to displacement of populations of Phytophthora infestans in England and Wales. Eur. J. Plant Pathol. 103:379-391.

7. Dekker, J. 1984. The development of resistance to fungicides. Progr. Pestic. Biochem. Toxicol. 4:165-218.

8. Dorrance, A. E., Inglis, D. A., Derie, M. L., Brown, C. R., Goodwin, S. B., Fry, W. E., and Deahl, K. L. 1999. Characterization of Phytophthora infestans populations in Western Washington. Plant Dis. 83:423-428.

9. Dowley, L. J., and O'Sullivan, E. 1985. Monitoring metalaxyl resistance in populations of Phytophthora infestans. Potato Res. 28:531-534.

10. Drenth, A., Goodwin, S. B., Fry, W. E., and Davidse, L. C. 1993. Genotypic diversity of Phytophthora infestans in the Netherlands revealed by DNA polymorphisms. Phytopathology 83:1087-1092.

11. Drenth, A., Turkensteen, L. J., and Govers, F. 1993. The occurrence of the A2 mating type of Phytophthora infestans in the Netherlands; significance and consequences. Neth. J. Plant Pathol. 99(Suppl. 3):57-67.

12. Fry, W. E., Drenth, A., Spielman, L. J., Mantel, B. C., Davidse, L. C., and Goodwin, S. B. 1991. Population genetic structure of Phytophthora infestans in the Netherlands. Phytopathology 81:1330-1336.

13. Fry, W. E., and Goodwin, S. B. 1997. Resurgence of the Irish Potato Famine fungus. BioScience 47:363-371.

14. Fry, W. E., Goodwin, S. B., Dyer, A. T., Matuszak, J. M., Drenth, A., Tooley P. W., Sujkowski, L. S., Koh, Y. J., Cohen, B. A., Spielman, L. J., Deahl, K. L., Inglis, D. A., and Sandlan, K. P. 1993. Historical and recent migrations of Phytophthora infestans: Chronology, pathways, and implications. Plant Dis. 77:653-661

15. Fry, W. E., Goodwin, S. B., Matuszak, J. M., Spielman, L. J., Milgroom, M. G., and Drenth, A. 1992. Population genetic structure and intercontinental migrations of Phytophthora infestans. Annu. Rev. Phytopathol. 30:107-129.

16. Gallegly, M. E., and Galindo, J. 1958. Mating type and oospores of Phytophthora infestans in nature in Mexico. Phytopathology 48:274277.

17. Goodwin, S. B., Cohen, B. A., and Fry, W. E. 1994. Panglobal distribution of a single clonal lineage of the Irish potato famine fungus. Proc. Natl. Acad. Sci. USA 91:11591-11595.

18. Goodwin, S. B., Drenth, A., and Fry, W. E. 1992. Cloning and genetic analysis of two highly polymorphic, moderately repetitive nuclear DNAs from Phytophthora infestans. Curr. Genet. 22:107-115.

19. Goodwin, S. B., Spielman, L. J., Matuszak, J.
M., Bergeron, S. N., and Fry, W. E. 1992 Clonal diversity and genetic differentiation of Phytophthora infestans populations in northern and central Mexico. Phytopathology 82:955-961.

20. Goodwin, S. B., Sujkowski, L. S., and Fry, W. E. 1994. Metalaxyl-resistant clonal genotypes of Phytophthora infestans in the United States and Canada were probably introduced from Northwestern Mexico. (Abstr.) Phytopathology 84:1079.

21. Griffith, G. W., and Shaw, D. S. 1998. Polymorphisms in Phytophthora infestans: Four mitochondrial haplotypes are detected after PCR amplification of DNA from pure cultures or from host lesions. Appl. Environ. Microbiol. 64:4007-4014.

22. Henn, G., Van der Mescht, A., and Kistner, M. 1993. The use of isozymes to detect somaclonal variation in plants from cell suspensions of potato cv. BP1. J. South Afr. Soc. Hortic. Sci. 3:104-105.

23. Hohl, H. R., and Iselin, K. 1984. Strains of Phytophthora infestans with A2 mating type behaviour. Trans. Br. Mycol. Soc. 83:529530.

24. Kato, M., and Fry, W. E. 1995. Fitness components and tolerance to mancozeb among genotypes of Phytophthora infestans in the United States. (Abstr.) Phytopathology 85:1131.

25. Kato, M., and Fry, W. E. 1995. Competitive fitness of a new and old lineage of Phytophthora infestans in the USA. (Abstr.) Phytopathology 85:1557.

26. Koh, Y. J., Goodwin, S. B., Dyer, A. T., Cohen, B. A., Ogoshi, A., Sato, N., and Fry, W. E. 1994. Migration and displacement of Phytophthora infestans populations in east Asian countries. Phytopathology 84:922-927.

27. Lambert, D. H., and Currier, A. I. 1997. Differences in tuber rot development for North American clones of Phytophthora infestans. Am. Potato J. 74:39-43.

28. Legard, D. E., Lee, T. Y., and Fry, W. E. 1995. Pathogenic specialization in Phytophthora infestans: Aggressiveness on tomato. Phytopathology 85:1356-1361.

29. Oudemans, P., and Coffey, M. D. 1991. Isozyme comparison within and among worldwide sources of three morphologically distinct species of Phytophthora. Mycol. Res. 95:19-30.

30. Robertson, E. F., Dannely, H. K., Malloy, P. J., and Reeves, H. C. 1987. Rapid isoelectric focusing in a vertical polyacrylamide minigel system. Anal. Biochem. 167:290-294.

31. Smart, C. D., Willmann, M. R., Mayton, H., Mizubuti, E. S. G., Sandrock, R. W., Muldoon, A. E., and Fry, W. E. 1998. Self-fertility in two clonal lineages of Phytophthora infestans. Fungal Genet. Biol. 25:134-142.

32. Spielman, L. J., Drenth, A., Davidse, L. C., Sujkowski, L. J., Gu, W., Tooley, P. W., and Fry, W. E. 1991. A second world-wide migration and population displacement of Phytophthora infestans? Plant Pathol. 40:422430 .

33. Tantius, P. H., Fyfe, A. M., Shaw, D. S., and Shattock, R. C. 1986. Occurrence of the A2 mating type and self fertile isolates of Phytophthora infestans in England and Wales. Plant Pathol. 35:578-581.

34. Therrien, C. D., Tooley, P. W., Spielman, L. J., Fry, W. E., Ritch, D. L., and Shelly, S. E. 1993. Nuclear DNA content, allozyme phenotypes and metalaxyl sensitivity of Phytophthora infestans from Japan. Mycol. Res. 97:945-950. 